\title{
A FÍSICA NO ENSINO MÉDIO TÉCNICO INTEGRADO EM EDIFICAÇÕES NO INSTITUTO FEDERAL DA BAHIA: UMA ANÁLISE A PARTIR DO PROJETO PEDAGÓGICO DO CURSO
}

\author{
Danilo Almeida Souza*, Maria Cristina Martins Penido \\ *E-mail: danilofisico@gmail.com \\ Instituto Federal de Educação, Ciência e Tecnologia da Bahia, Brasil \\ DOI: 10.15628/rbept.2020.8994
}

Artigo submetido em set/2019 e aceito em fev/2020

\begin{abstract}
RESUMO
Este artigo apresenta uma discussão sobre a disciplina de Física no Ensino Médio Integrado (EMI) no curso de edificações do Instituto Federal da Bahia (IFBA). A pesquisa é de natureza qualitativa e avalia, a partir da análise dos Projetos Pedagógico do Curso (PPC) de cinco campi, como os elementos da parte dedicada a Física remetem ao EMI defendido por teóricos do campo da educação e trabalho, e como se dá sua articulação com as disciplinas do núcleo tecnológico. Esta pesquisa justifica-se por estudos ainda escassos no ensino de ciências que discutam o currículo dessas disciplinas no universo da educação profissional técnica. Nossos resultados apontam a semelhança do currículo da Física no EMI com o do ensino médio regular. Especialmente para o curso de edificações, indicamos a possibilidade de construírmos currículos que agreguem os fundamentos da Física apoiado no universo profissional e que garantam a mesma ou maior capacidade de formação a partir de uma integração mais efetiva.
\end{abstract}

Palavras-Chave: Ensino Médio Integrado. Educação Profissional. Ensino de Física

\section{PHYSICS IN TECHNICAL EDUCATION INTEGRATED IN BUILDINGS IN THE BAHIA FEDERAL INSTITUTE: AN ANALYSIS FROM THE COURSE PEDAGOGICAL PROJECT}

\begin{abstract}
This article presents a discussion on the subject of Physics in Integrated High School (IHS) in the building course of the Federal Institute of Bahia (IFBA). The research is of a qualitative nature and evaluates, based on the analysis of the Course Pedagogical Projects (CPP) of five campuses, how the elements of the part dedicated to Physics refer to the IHS defended by theorists from the field of education and work, and how it happens its articulation with the disciplines of the technological nucleus. This research is justified by studies that are still scarce in science education that discuss the curriculum of these disciplines in the universe of technical professional education. Our results show the similarity of the Physics curriculum at IHS with that of regular high school. Especially for the building course, we indicate the possibility of building curricula that aggregate the fundamentals of Physics supported by the professional universe and that guarantee the same or greater training capacity from a more effective integration.
\end{abstract}

Key-words: Integrated High School. Professional education. Physics Teaching 


\section{INTRODUÇÃO}

O debate acerca da educação profissional no Brasil tanto no âmbito de pesquisadores em educação, quanto por parte dos docentes que exercem sua atividade profissional em instituições que ofertam o ensino técnico, tem crescido consideravelmente, sobretudo pelo aumento no número de vagas ocorrido com a expansão da Rede Federal de Educação Profissional, Científica e Tecnológica a partir dos anos 2000, consolidados com a ascensão do governo do PT com a eleição do ex-presidente Lula e início do governo a partir do ano de 2003. É nesse ínterim, a partir da mobilização de educadores, que há um olhar especial ao Ensino Médio Integrado (EMI), aquele que, nas

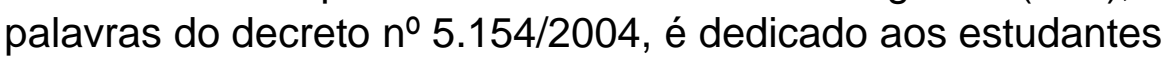

que já tenha concluído o ensino fundamental, sendo o curso planejado de modo a conduzir o aluno à habilitação profissional técnica de nível médio, na mesma instituição de ensino, contando com matrícula única para cada aluno. (BRASIL, 2004).

A importância do decreto no 5.154/2004 se dá por simbolizar uma retomada a um modelo de ensino que tinha grande êxito no âmbito das escolas federais, e que havia sido interrompido pelo projeto de governo anterior, por meio do decreto no 2.208/97 que proibia a possibilidade de articulação entre a educação básica de nível médio com a formação profissional, sendo permitido apenas sua oferta a partir das formas subsequente (pós ensino médio) ou concomitante ${ }^{1}$. Apesar da Rede Federal se manter isenta a boa parte das mudanças que ocorrera no sistema de educação brasileira no seu sentido amplo, dessa vez seu processo autônomo na oferta de educação profissional, no modelo que julgasse mais conveniente (que apresentava bons resultados, seja na formação de técnicos especializados ou na preparação de bons alunos para $O$ ingresso em instituições de ensino superior), estava fortemente ameaçado. A mudança provocada pela nova legislação era um indicativo para priorização de formações rápidas, que atendesse ao dinamismo e às necessidades do setor produtivo e econômico, refletindo numa educação imediatista, com ausência de pensamento crítico e autônomo.

Damos uma atenção especial ao EMI, por se tratar de um modelo de oferta de Ensino Médio que traz muitas das características preconizadas por teóricos Marxistas do que seria uma educação para a classe trabalhadora, num claro modelo contra-hegemônico. Dermeval Saviani, na sua abordagem sobre o que seria Educação Politécnica, entendida como uma "especialização com

\footnotetext{
${ }^{1}$ A educação profissional na forma concomitante é oferecida somente a quem já tenha concluído o ensino fundamental ou esteja cursando o ensino médio, na qual a complementaridade entre a educação profissional técnica de nível médio e o ensino médio pressupõe a existência de matrículas distintas para cada curso (técnico e médio), podendo ocorrer na mesma instituição de ensino ou não.
} 
domínio dos fundamentos científicos das diferentes técnicas utilizadas na produção moderna" (SAVIANI, 2007, p. 161), é um dos mais citados quando se fala em educação profissional tanto por apontar caminhos de se pensar 0 currículo na educação profissional, como por abordar os fundamentos teóricos desse tipo de ensino. Comentando as palavras do autor, seria pensar em uma educação que dê conta dos fundamentos básicos da ciência, mas não deixe de lado a assimilação de processos e técnicas voltados para a formação profissional, rompendo o modelo de formar o estudante apenas para instrumentalizar que serve basicamente aos interesses do capital.

A Rede Federal tem um papel importante na oferta de EMI. Por meio da criação dos Institutos Federias pela lei № 11.892 de 28 de dezembro de 2008, houve um aumento significativo na oferta de ensino na forma integrada, já que estava previsto nos objetivos dessas instituições no seu artigo $7^{\circ}$ a obrigatoriedade em ofertar educação profissional e tecnológica em todos os níveis de ensino, prioritariamente, numa razão de cinquenta por cento, na forma de cursos técnicos de nível médio na forma integrada para os concluintes do ensino fundamental e para o público da educação de jovens e adultos. Mais do que isso, a interiorização e a implementação da política de cotas que vieram acompanhadas com a expansão abriu as portas das instituições da rede federal para os filhos da classe trabalhadora, que ainda eram minorias nessas instituições, oportunizando a eles uma educação pública com referenciada qualidade, o que deveria ser comum a toda população brasileira.

O EMI seria uma maneira de diminuir o dualismo histórico presente no Ensino Médio em todo o percurso da educação, que dividia tipos de educação distintos para jovens de diferentes classes econômicas/sociais, o que limitava 0 poder de escolha dos estudantes ao término do ensino médio à qualidade da formação que the era oferecida. Preparar para o ingresso no ensino superior, ou para o mercado de trabalho? Ciavatta (2012, p. 85), apresenta o que seria essa formação integrada no seu aspecto mais amplo:

A ideia de formação integrada sugere superar o ser humano
dividido historicamente pela divisão social do trabalho entre a
ação de executar e a ação de pensar, dirigir ou planejar. Trata-
se de superar a redução da preparação para o trabalho ao seu
aspecto operacional, simplificado, escoimado dos
conhecimentos que estão na sua gênese científico-tecnológica
e na sua apropriação histórico-social. Como formação humana,
o que se busca é garantir ao adolescente, ao jovem e ao adulto
trabalhador o direito a uma formação completa para a leitura do
mundo e para a atuação como cidadão pertencente a um país,
integrado dignamente à sua sociedade política. Formação que,
nesse sentido, supõe a compreensão das relações sociais
subjacentes a todos os fenômenos.

Quando nos voltamos para a área de Ensino de Ciências/ Física, é notável a restrição de pesquisas que lidem com a análise do ensino dessas disciplinas na educação profissional técnica de nível médio, e quando o tema é 
trazido, o foco está em avaliar metodologias ou estratégias de ensino para esse público sem uma preocupação com os fundamentos que perpassam 0 EMI.

Se olharmos a ata do último Simpósio Nacional de Ensino de Física (SNEF) realizado na cidade de Salvador- BA, que passa a incorporar a área temática "06- O Ensino de Física na Educação Profissional", vemos a quantidade ínfima de trabalhos aprovados inseridos nessa linha. Das comunicações orais, apenas o trabalho de nossa autoria integra a área temática (SOUZA; PENIDO, 2019). Na Sessão de painéis, esse número sobe para dois, no entanto, continua sem grande representatividade, pois, apesar de esses estudos englobarem o universo do ensino profissional técnico, seus objetos de estudo são outros. Franca (2019) traz uma sequência didática para a abordagem de conceitos de mecânica quântica utilizando os raios $X$ sob a perspectiva sociocultural, já Rocha e Melo (2019) aborda um relato de experiência, cujo objetivo é descrever a elaboração e aplicação de um material paradidático distribuído para alunos de uma turma de nutrição do ensino técnico profissionalizante para o estudo da calorimetria, enquanto fundamentase na teoria da aprendizagem significante de Carl Rogers.

Uma exceção está no trabalho de Garcia (1995), no qual o autor apresenta uma discussão sobre o ensino de Física nas Escolas Técnicas Federais, buscando identificar de que forma e sob que condições a Física é ensinada nas escolas da Rede Federal de Ensino Técnico Industrial (embora nesse momento o ensino técnico na Rede Federal não carregasse o nome de Ensino Médio Integrado, na época de realização da pesquisa a configuração era muito próxima do que é praticado hoje nos Institutos Federais). Aqui, embora com objetivos semelhantes, a pesquisa centra-se na questão curricular e é feita num novo contexto, no qual está vigente a Lei de Diretrizes e Base da Educação de 1996 (e suas alterações), a institucionalização do Ensino Médio Integrado (no âmbito nacional, inclusas aqui todas as redes) e a expansão e interiorização da Rede Federal nos estados brasileiros, o que significa novo público, novas demandas e novos interesses para esse ensino profissional técnico.

Neste artigo trazemos uma discussão sobre a Física no EMI a partir da análise dos PPCs do curso técnico integrado em edificações de cinco campi do Instituto Federal da Bahia. Em termos de estrutura, saímos da introdução avançando para uma discussão teórica do que seria esse Ensino Médio Integrado. A partir daí vamos à metodologia, onde apresentamos a modalidade de pesquisa, indicando o percurso metodológico traçado e as razões que justifiquem sua escolha; em seguida trazemos a análise do PPC orientados por critérios preliminarmente delimitados; por fim, apresentamos nossas considerações, apontando caminhos, as limitações do estudo e as perspectivas futuras. 


\section{AFINAL DE CONTAS, O QUE É ESSE ENSINO MÉDIO INTEGRADO? 0 SENTIDO DA INTEGRAÇÃO}

No seu texto sobre formação integrada, Ciavatta (2012), traz uma discussão sobre o sentido do termo "integrar" e como ele deve ser incorporado a educação, defendendo que a educação geral se torne parte inseparável da educação profissional. Daqui talvez surja a confusão sobre o que viria a ser o ensino médio integrado e como se daria sua execução. Construir uma educação integrada é muito mais que apenas aglutinar um conjunto de conhecimentos técnicos científicos, junto aos próprios do ensino médio regular. Como veremos nessa seção, envolve uma série de mudanças estruturais e de concepção que vão desde apropriar-se de uma realidade e, no coletivo, a partir dos conhecimentos de cada disciplina, entender como essas áreas podem contribuir para a formação do sujeito.

Em termos de concepção do ensino médio integrado, os textos de Ramos $(2008,2012)$ nos apresentam três sentidos para o processo de integração, os quais tomamos como base para pensarmos o ensino médio integrado. O primeiro, dedicado a formação omnilateral, que incorpora a formação humana, trazendo todos os sentidos da vida para a formação do indivíduo. No segundo, a indissociabilidade entre educação profissional e educação básica (como forma de relacionar ensino médio e educação profissional), onde é destacado o percurso político e social no qual foi sendo construído a ideia de profissionalização do ensino médio, destacando a ideia de que hoje já não se tem a preparação profissional no ensino médio como uma política compensatória para aqueles que não teriam acesso ao ensino superior, nem como uma necessidade da economia brasileira. Pelo contrário, há uma movimentação no sentido de desvincular as finalidades do ensino médio do mercado de trabalho e colocá-las sobre as necessidades dos sujeitos. No terceiro sentido da integração, nomeado pela autora de integração de conhecimentos gerais e específicos como totalidade, é discutida a relação entre a parte e a totalidade na proposta curricular do ensino médio integrado, onde, por fim, nos é apresentado uma proposta para o desenho de um currículo integrado.

No primeiro sentido de integração temos uma retomada da concepção de escola unitária, a partir dos eixos de trabalho, ciência e cultura. A perspectiva de escola unitária, tomando o trabalho como princípio educativo, é defendida por muitos autores atuantes no campo da educação profissional, como Moura (2007), Ramos (2008), Ramos (2012), Frigotto, Ciavatta e Ramos (2012) e Ciavatta (2012). Trazer o trabalho associado à ciência e à cultura estaria sintetizado ao tomarmos o trabalho como princípio educativo, o que nas palavras de Ramos (2008, p.22), reflete em "o ser humano produtor de sua realidade e, por isto, se apropria dela e pode transformá-la". As reflexões de Ramos (2008) inspiram-se no que está defendido por Saviani (1989, p.12) quando apresenta uma discussão sobre Politecnia, reafirmando que o trabalho, 
desde o advento do capitalismo, seria o balizador para os pilares da sociedade moderna, inclusive para o sistema de educação, universalização do ensino e construção dos currículos.

A indissociabilidade entre educação profissional e educação básica hoje já é garantida em termos de legislação educacional quando se toma como referência os Institutos Federais, onde é valorizada dentro das modalidades de ensino ofertada, o ensino médio integrado. Mais do que uma possibilidade de formação, alguns trabalhos como o de Simões (2007), que defendem essa forma de ensino, enfatizam que esse tipo de formação se torna quase uma necessidade, sobretudo para os jovens de classe menos favorecidas, sendo assim "um modo de fortalecer os jovens trabalhadores em sua emancipação e desenvolvimento pessoal e coletivo."

O Ensino Técnico articulado com o Ensino Médio, preferencialmente Integrado, representa para a juventude uma possibilidade que não só colabora na sua questão da sobrevivência econômica e inserção social, como também uma proposta educacional, que na integração de campos do saber, torna-se fundamental para os jovens na perspectiva de seu desenvolvimento pessoal e na transformação da realidade social em que estão inseridos. A relação e integração da teoria e prática, do trabalho manual e intelectual, da cultura técnica e da cultura geral, interiorização e objetivação vão representar um avanço conceitual e a materialização de uma proposta pedagógica avançada em direção a politecnia como configuração da educação média de uma sociedade póscapitalista. (SIMÕES, 2007, p. 84).

Assim, por mais que existam críticas quanto a profissionalização precoce de adolescentes, a realidade do Brasil, em sua maioria constituída de pessoas com baixo poder aquisitivo, nos impõe a pensar um ensino médio que garanta a aquisição de conhecimento teórico, pensado na formação humana e nas relações sociais existentes, mas que também habilite o indivíduo a uma profissão que garanta sua subsistência, numa estrutura em que vivemos da força de trabalho, seja ela vendida ao estado ou a iniciativa privada. São a esses anseios que atende o ensino médio integrado.

O desafio de se construir uma proposta para o ensino médio integrado tem sido inspiração de alguns estudos e é apresentado por Ramos (2008, 2012) como o terceiro sentido da integração. Quando nos voltamos para a organização de disciplinas, Ramos (2012, p. 122) defende que toda movimentação no sentido de buscar-se a integração possa nascer a partir da articulação de trabalhos que passeiem dentro da interdisciplinaridade, mas que mantenham sua organização estrutural nas suas disciplinas, uma vez que a organização por competências, por exemplo, não seria suficiente para superar práticas pedagógicas que visam apenas a transmissão de conteúdos e 0 aspecto dual dessa forma de organização, ao contrário, em certos aspectos, poderia até mesmo agravar esse tensionamento. A partir dos argumentos 
apresentados pela autora, é possível verificar seu posicionamento quanto ao fato que a estruturação de planos de curso, por disciplinas/componentes curriculares seja a melhor forma de abordar os aspectos teóricos de modo a levar o entendimento das teorias apresentadas nas disciplinas do núcleo comum para o contexto em que foram construídas, tornando o conhecimento prático mais significativo a partir de um aspecto teórico consolidado.

Pensando especificamente na questão da organização curricular, tem sido consenso que apenas um projeto que agregue as disciplinas da formação geral e de formação específica sem a proposição de um diálogo entre elas, não é suficiente para construir um modelo de educação integrada, isso está evidenciado em Moura (2007), Ramos $(2008,2012)$ e no documento base para a Educação Profissional Técnica de Nível Médio (MOURA; GARCIA; RAMOS, 2007). Moura, por exemplo propõe que

\begin{abstract}
as disciplinas deverão estar articuladas através de um eixo integrador que corresponda à área profissional na qual está situado cada curso. Também contribuindo para a integração o fato de os alunos estarem imersos em um ambiente de estudos relativos às ciências, às letras e às artes juntamente com a formação profissional tanto na própria área, como em outras áreas profissionais. (MOURA, 2007, p. 27).
\end{abstract}

Dessa forma, os documentos norteadores que orientam o desenrolar dos cursos técnicos, como o PPC, é de fundamental importância para verificar o quanto esses cursos na forma de ensino médio integrado agregam a natureza de educação politécnica que orienta o tipo de organização do ensino médio técnico que surge com o decreto no 5.154/2004. É nesse sentido que caminha este artigo.

Assim, buscamos investigar como está empregada a ideia de Ensino Médio Integrado na descrição do componente curricular da Física nos cursos ofertados pelo Instituto Federal da Bahia (partindo da realidade do curso técnico em edificações), bem como apontar caminhos de modo a alinhar o que está posto no documento institucional, com o preconizado na literatura.

\title{
3 METODOLOGIA
}

Adotamos como modalidade de investigação neste artigo a pesquisa empírica de caráter qualitativo, tomando a análise dos PPCs do curso Técnico Integrado em Edificações, no Instituto Federal da Bahia (IFBA), campi de Barreiras, Eunápolis, Feira de Santana, Ilhéus e Salvador.

A escolha do curso/campi a ser pesquisado partiu do critério de se ter um curso de Ensino Médio Integrado que tivesse presente em campus implantados em três momentos distintos na evolução da Rede Federal de Educação Profissional, Científica e Tecnológica, desde seu embrião enquanto 
Escolas de Aprendizes Artífices em 1909. Como primeiro momento, elegemos o nascimento da Rede Federal de educação profissional, ou seja o campus que deu origem ao que hoje seria o IFBA, nesse caso, o campus Salvador. Para o segundo momento, tomamos aqueles campi que experimentaram o processo de transição entre a oferta de ensino médio regular e formação técnica dissociados (aspecto dual) para a oferta de ensino médio na forma integrada que começou a ser implantada a partir de 2004 por meio do decreto $\mathrm{n}^{\circ}$ 5.154/04. Por fim, para o terceiro grupo, tomamos aqueles que nasceram após a nova identidade da instituição, já enquanto Instituto Federal de Educação, Ciência e Tecnologia, resultante do processo de expansão da rede e que, naturalmente, vivenciam desde o seu nascimento a oferta de ensino médio na forma integrada, inclusive com proporção definida em lei, quanto ao número de oferta de vagas que deveriam acontecer nessa forma.

Nossa expectativa era que o contexto histórico de implantação dos campi influenciasse na concepção de ensino médio integrado dessas localidades, que deveria reverberar na descrição dos PPCs. Ao mesmo tempo, a adoção desse critério deveria aproximar a realidade da Instituição IFBA para nosso universo de pesquisa, mesmo que a investigação não tenha sido realizada pela análise da totalidade dos cursos de EMI ofertados na instituição.

Com base nos dados do processo seletivo (PROSEL) do IFBA, para ingresso de estudantes no ano de 2018 (IFBA, 2018), apenas o curso de Ensino Médio Integrado em Edificações cumpria esse quesito.

Quadro 1 - Categoria dos campi pesquisados, em função dos critérios estabelecidos pelos pesquisadores.

\begin{tabular}{|c|c|c|}
\hline \multirow{4}{*}{ 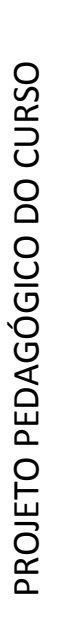 } & Categorização & Campus \\
\hline & Campus embrião do IFBA & Salvador \\
\hline & $\begin{array}{l}\text { Campus que experimentaram a transição } \\
\text { entre a oferta do ensino médio dissociado } \\
\text { ao ensino técnico e o ensino médio } \\
\text { integrado a partir da publicação do } \\
\text { Decreto no } 5.154 / 04\end{array}$ & Barreiras e Eunápolis \\
\hline & $\begin{array}{l}\text { Campus pertencente a Rede Federal na } \\
\text { Bahia, nascido da expansão já no âmbito } \\
\text { dos institutos federais de educação } \\
\text { tecnológica }\end{array}$ & Feira de Santana e Ilhéus \\
\hline
\end{tabular}

Fonte: Elaboração dos autores.

Buscamos, a partir da análise dos PPCs, verificar na descrição do componente curricular da Física: i) Quais elementos fazem menção a contribuição da Física para a constituição da educação politécnica; ii) Como 
está distribuída e apresentada a disciplina Física no decorrer das etapas para conclusão do ensino médio integrado (carga horária dedicada, conteúdos abordados, etc.); iii) Quais elementos do componente curricular da Física fazem referência a formação profissional técnica pretendida; e iv) Quais conteúdos comuns a disciplina de Física estão presentes em disciplinas da formação técnica.

Informamos que esta Pesquisa, integra o projeto O CURRíCULO DA FÍSICA DENTRO DO ENSINO MÉDIO INTEGRADO: A CONCEPÇÃO DOS PROFESSORES, OS DOCUMENTOS OFICIAIS E IMPLICAÇÕES PARA O ENSINO, registrado sob o Certificado de Apresentação para Apreciação Ética (CAAE) no 02170918.0.0000.5031 e aprovado em 27/11/2018 através do parecer 3.041.998, CEP/ IFBA.

\section{ANÁLISE DOS PROJETOS PEDAGÓGICOS DE CURSO: COMO ESTÁ APRESENTADA A DISCIPLINA DE FÍSICA?}

Inicialmente, pontuamos que, conforme consta no Catálogo Nacional de Cursos Técnicos, o curso Técnico em Edificações deve ser ofertado com o mínimo de 1200 horas, possibilitado a verticalização do ensino para ensino tecnológico em nível de graduação ou a certificação de habilidades adquiridas no eixo formativo, dentro daquilo que chamamos de Certificação Intermediária em Cursos de Qualificação Profissional (BRASIL, 2016, p. 45). Ao nos voltarmos para os cursos na forma integrada, além de cumprido esse requisito, como preconiza a Lei de Diretrizes e Base da Educação de 1996, lei no 9.394/1996, deve-se atentar para a garantia dos 200 dias letivos, com uma carga horária mínima anual de 800 horas (BRASIL, 1996). Assim, todos os cursos técnicos em Edificações na forma integrada no Instituto Federal da Bahia obedecem a esse requisito mínimo legal (Nossa pesquisa não leva em conta a reforma do ensino médio, uma vez que a lei $n^{\circ}$ 13.415/2017 não foi utilizada como parâmetro para a construção dos PPCs que estão sendo analisados).

Embora nossa linha de investigação centre-se no PPC, achamos de extrema importância destacar a missão do Instituto Federal da Bahia (IFBA) que, conforme consta no seu Projeto Pedagógico Institucional (PPI), é "promover a formação do cidadão histórico-crítico, oferecendo ensino, pesquisa e extensão com qualidade socialmente referenciada, objetivando o desenvolvimento sustentável do país" (IFBA, 2013, p. 27). Isso é feito de modo a verificarmos 0 quanto o projeto que norteia as ações da instituição se alinha às concepções de educação politécnica.

O PPI deixa explícito que a formação do profissional técnico baseia-se na quebra da dicotomia entre o trabalho intelectual e o trabalho manual, prevendo uma formação que possibilite escolhas múltiplas frente às habilidades adquiridas. Isso fica claro no documento quando ele evidencia que 
o profissional técnico "é um ser reflexivo e crítico que possui funções intelectuais e instrumentais, habilitado por sua formação profissional" (IFBA, 2013 , p. 33). Os pressupostos teóricos que sustentam a construção do PPI estão apresentados e discutidos na seção dedicada aos princípios filosóficos e teórico-metodológicos gerais que norteiam as práticas acadêmicas da instituição e são de acesso público ${ }^{2}$. Ressalte-se que os princípios filosóficos expressos no PPI baseiam-se em teóricos do campo Marxista.

$\mathrm{Na}$ questão do currículo, o PPI é claro ao considerar que as normas de ensino devem ser direcionadas a atender as Diretrizes Curriculares Nacionais, para o Ensino Médio e para o Ensino Técnico (as diretrizes mencionadas no PPI, referem-se às publicadas em 2012. São elas que dão o direcionamento para a construção dos PPCs analisados), acrescendo-se o fato que

os currículos devem, ainda, ter compromisso com as realidades locais dos campi, visando atender as carências existentes e combater as desigualdades para alcançar o desenvolvimento socioeconômico, ambiental e tecnológico regional. Portanto, buscar uma concepção de currículo que aproxime mais o aluno das práticas de sua profissão. (IFBA, 2013, p. 48).

Dito isso, entendemos que a organização das disciplinas que compõem a matriz curricular dos cursos deve possibilitar uma aproximação do aluno a sua prática profissional, bem como aos fundamentos básicos das ciências naturais e humanas, que lhe possibilite a execução desse exercício profissional a partir de uma visão reflexiva e do seu papel na sociedade.

Para organização dessa seção, embora nossas questões norteadoras partam da avaliação da parte dedicada ao componente curricular da Física, achamos importante dedicar uma parte ao que chamamos de Prática Profissional Articuladora (PPA), que aparece no PPC do curso de edificações do campus de Barreiras.

\subsection{A Prática Profissional Articuladora (PPA)}

A Prática Profissional Articuladora (PPA) aparece descrita no PPC do curso de edificações do campus Barreiras, expressando que é seu objetivo "articular horizontalmente 0 conhecimento dos três anos do curso oportunizando o espaço de discussão e um espaço aberto para entrelaçamento entre as disciplinas" (IFBA/Campus Barreiras, 2016, p. 142-143). Para o curso técnico em edificações de Barreiras, a PPA contempla um total de 210 horas e a distribuição dessa carga horária e disciplinas envolvidas são determinadas conforme decisão do conselho de curso, nesse caso estruturadas conforme apresentado na Figura 1.

\footnotetext{
${ }^{2}$ Para acesso ao PPI: http://portal.ifba.edu.br/menu-institucional/documento/documentosinstitucionais
} 
Figura 1 - Distribuição das disciplinas na PPA no decorrer de cada ano letivo. Fonte: PPC do campus Barreiras. (IFBA/Campus Barreiras, 2016, p. 143)

\begin{tabular}{|c|c|c|c|c|}
\hline Ano & $\begin{array}{c}\text { Carga } \\
\text { Horária } \\
\text { Anual }\end{array}$ & Disciplinas* & $\begin{array}{l}\text { Carga } \\
\text { Horária } \\
\text { das } \\
\text { Disciplinas }\end{array}$ & Observaçōes \\
\hline $1^{\circ}$ & $90 \mathrm{~h}$ & $\begin{array}{c}\text { Desenho Arquitetônico I } \\
\text { Informática Aplicada } \\
\text { Geografia } \\
\text { Sociologia } \\
\end{array}$ & $\begin{array}{l}25 h \\
25 h \\
20 h \\
20 h \\
\end{array}$ & \\
\hline $2^{\circ}$ & $60 \mathrm{~h}$ & $\begin{array}{c}\text { Tecnologia das Construçōes } \\
\text { Biologia } \\
\text { Quimica } \\
\text { Português } \\
\end{array}$ & $\begin{array}{l}25 \mathrm{~h} \\
10 \mathrm{~h} \\
10 \mathrm{~h} \\
15 \mathrm{~h}\end{array}$ & \\
\hline $3^{\circ}$ & $60 \mathrm{~h}$ & $\begin{array}{c}\text { Instalaçōes Elétrica } \\
\text { Instalaçōes Hidrossanitárias } \\
\text { Fisica } \\
\text { Matemática } \\
\end{array}$ & $\begin{array}{l}20 \mathrm{~h} \\
20 \mathrm{~h} \\
10 \mathrm{~h} \\
10 \mathrm{~h}\end{array}$ & \\
\hline
\end{tabular}

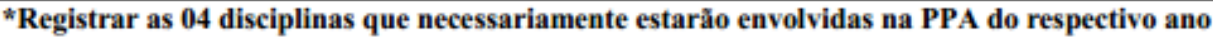

Fonte: PPC do campus Barreiras. (IFBA/Campus Barreiras, 2016, p. 143).

Não há dúvidas de que a inclusão da PPA é um passo importante para execução de cursos integrados no IFBA, embora não seja possível entender sua operacionalização apenas pela descrição presente no documento. O PPC relata que a PPA ocorrerá ao longo das unidades letivas, orientadas pelos docentes titulares das disciplinas.

Estas práticas deverão estar contempladas nos projetos de PPA elaborados antes do início letivo em que as PPA serão desenvolvidas, ou no máximo, até vinte dias úteis a contar do primeiro dia letivo do ano. O projeto de PPA será assinado, aprovado e arquivado juntamente com o plano de ensino de cada disciplina envolvida. (IFBA/Campus Barreiras, 2016, p. 143-144)

Nossa leitura é que há uma indefinição de como acontece a Prática Profissional Articuladora na ausência do projeto de PPA quando do início do ano letivo. Damos destaque ao papel do coordenador de curso nesse quesito, quando o PPC enfatiza a sua responsabilidade de promover reuniões periódicas (no mínimo duas) para que os docentes orientadores das práticas profissionais possam interagir, planejar e avaliar em conjunto com todos os docentes do curso a realização e o desenvolvimento das PPA.

A existência da PPA apenas no plano do curso de edificações do campus Barreiras aponta para um curso reformulado recentemente e que deve ter tido sua construção regida por normas administrativas mais atuais. Baseados nesse comportamento singular, nossa busca nos levou ao conhecimento da Instrução Normativa Pedagógica para Reformulação Curricular dos Cursos da Educação Profissional Técnica de Nível Médio, Forma Integrada, aprovado pela resolução CONSUP, no 30/CONSUP, de 24/05/2016 
(IFBA, 2016), que traz na sua proposta um alinhamento para a construção e reformulação dos planos de curso do IFBA. É nesse documento que estão presentes as diretrizes da Prática Profissional Articulada e sua presença obrigatória para os novos PPCs submetidos à apreciação. Como ponto positivo, indicamos que essa instrução normativa traz um avanço em uniformizar a estrutura dos planos de cursos técnicos de nível médio na forma integrada do IFBA, além de instituir uma ação concreta que vise o trabalho conjunto das diferentes áreas de conhecimento e disciplinas por meio da PPA.

A Instrução Normativa destaca o papel das PPA em agregar conhecimentos da área básica e da área técnica, como também, a integração entre as disciplinas básicas e as disciplinas técnicas. Tal norma é desenvolvida em forma de projetos, sendo um componente com espaço próprio na matriz curricular. Seus objetivos são:

I - ampliar a compreensão sobre as áreas de atuação do curso, assim como o perfil do egresso; II - vincular, de forma efetiva, a formação dos estudantes com o mundo do trabalho; III - promover a construção articulada do conhecimento por meio do diálogo entre os diferentes componentes curriculares; IV - viabilizar a efetiva aplicação da prática profissional específica de cada curso por meio do contato com situações reais de trabalho; $\mathrm{V}$ - possibilitar uma reflexão permanente sobre o campo de atuação do curso; VI - promover a inserção da pesquisa como princípio educativo. (IFBA, 2016, p. 20-21).

Destacamos que a realização da PPA é um movimento no sentido de incentivar espaços de integração das áreas de conhecimento quando se fala em cursos integrados de nível médio. Como o próprio documento prevê, "a PPA não exclui as demais formas de integração que possam vir a complementar a formação dos estudantes ampliando seu aprendizado". É nesse sentido que reafirmamos a questão fundamental que sustenta esse artigo que é a construção da integração, nascendo do espaço de cada disciplina a partir de objetivos apresentados pelo curso e que a partir disso, outras ações possam ser potencializadas como exemplo, a própria PPA.

\subsection{O Componente Curricular da Física}

Embora o Projeto Pedagógico Institucional (PPI) e uma parcela na descrição do PPC faça menção a formação do sujeito em sua plenitude, 0 tornando apto ao exercício de sua cidadania, bem como as habilidades técnicas que integram a sua formação, pontuamos que, na descrição do componente curricular da Física, não existem elementos que caminhem nesse sentido.

Quando paramos para analisar a distribuição e apresentação da disciplina de Física nos PPCs, em temos gerais temos uma proposição para a 
Física que se aproxima muito do que é feito no ensino médio regular. Basta um olhar atento a carga horária, aos conteúdos que são trazidos e como eles estão distribuídos (resguardado a autonomia do campus quanto a inclusão de alguns temas/conteúdos e a dedicação de 2 horas/aula ou 3 horas/aula por semana em cada ano letivo) (Ver Quadro 2).

Quadro 2 - Quadro resumo da distribuição da disciplina Física, nos cursos Técnicos Integrado em Edificações do Instituto Federal da Bahia.

\begin{tabular}{|c|c|c|c|}
\hline Campus & Ato de Aprovação & $\begin{array}{c}\text { Duração } \\
\text { do } \\
\text { Curso }\end{array}$ & $\begin{array}{c}\text { Carga horária/ } \\
\text { Apresentação da Disciplina Física }\end{array}$ \\
\hline 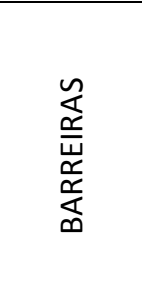 & $\begin{array}{l}\text { Aprovado, resolução no } 17 \text {, } \\
\text { de } 08 \text { de abril de } 2016 \text { (a } \\
\text { partir do ano letivo de } \\
2016 \text { ) }\end{array}$ & $\begin{array}{c}03 \\
\text { ANOS }\end{array}$ & $\begin{array}{l}\text { 10 ANO } 80 \text { horas/aula; } 60 \text { horas ( } 02 \text { aulas por } \\
\text { semana); } \\
\text { 20 ANO } 120 \text { horas/aula; } 90 \text { horas ( } 03 \text { aulas por } \\
\text { semana); } \\
\text { 3o ANO } 80 \text { horas/aula; } 60 \text { horas ( } 02 \text { aulas por } \\
\text { semana); } \\
\text { TOTAL } 210 \text { horas, ou } 280 \text { horas aulas }\end{array}$ \\
\hline 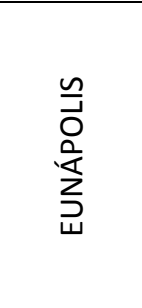 & $\begin{array}{l}\text { Aprovado, resolução no } 78 \text {, } \\
\text { de } 12 \text { de agosto de } 2014 \\
\text { (vigor na data de } \\
\text { publicação) }\end{array}$ & $\begin{array}{c}04 \\
\text { ANOS }\end{array}$ & $\begin{array}{l}\text { 10 ANO } 108 \text { horas/aula; } 90 \text { horas ( } 03 \text { aulas por } \\
\text { semana); } \\
\text { 20 ANO } 108 \text { horas/aula; } 90 \text { horas ( } 03 \text { aulas por } \\
\text { semana); } \\
\text { 3o ANO } 108 \text { horas/aula; } 90 \text { horas ( } 03 \text { aulas por } \\
\text { semana); } \\
\text { TOTAL } 270 \text { horas, ou } 324 \text { horas aulas }\end{array}$ \\
\hline 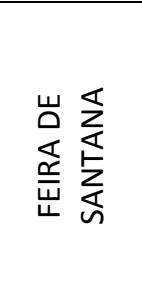 & $\begin{array}{l}\text { Aprovado, resolução no } 79 \text {, } \\
\text { de } 12 \text { de agosto de } 2014 \\
\text { (Vigor na data de } \\
\text { publicação) }\end{array}$ & $\begin{array}{c}04 \\
\text { ANOS }\end{array}$ & $\begin{array}{l}\text { 10 ANO } 108 \text { horas/aula; } 90 \text { horas ( } 03 \text { aulas por } \\
\text { semana); } \\
\text { 20 ANO } 108 \text { horas/aula; } 90 \text { horas ( } 03 \text { aulas por } \\
\text { semana); } \\
\text { 3o ANO } 108 \text { horas/aula; } 90 \text { horas ( } 03 \text { aulas por } \\
\text { semana); } \\
\text { TOTAL } 270 \text { horas, ou } 324 \text { horas aulas }\end{array}$ \\
\hline $\begin{array}{l}\text { 岂 } \\
\text { 坆 }\end{array}$ & $\begin{array}{l}\text { Aprovado, resolução no } 54 \text {, } \\
\text { de } 18 \text { de dezembro de } \\
2016 \text { (a partir do ano letivo } \\
\text { de } 2016.1 \text { ) }\end{array}$ & $\begin{array}{c}04 \\
\text { ANOS }\end{array}$ & $\begin{array}{l}\text { 10 ANO } 108 \text { horas/aula; } 90 \text { horas ( } 03 \text { aulas por } \\
\text { semana); } \\
\text { 20 ANO } 108 \text { horas/aula; } 90 \text { horas ( } 03 \text { aulas por } \\
\text { semana); } \\
\text { 3o ANO } 108 \text { horas/aula; } 90 \text { horas ( } 03 \text { aulas por } \\
\text { semana); } \\
\text { TOTAL } 270 \text { horas, ou } 324 \text { horas aulas }\end{array}$ \\
\hline 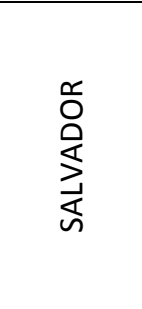 & $\begin{array}{l}\text { Aprovado, resolução no } \\
113 \text {, de } 12 \text { de agosto de } \\
2014 \text {, com vigência a partir } \\
\text { de } 2013\end{array}$ & $\begin{array}{c}04 \\
\text { ANOS }\end{array}$ & $\begin{array}{l}\text { 10 ANO } 108 \text { horas/aula; } 90 \text { horas ( } 03 \text { aulas por } \\
\text { semana); } \\
\text { 20 ANO } 108 \text { horas/aula; } 90 \text { horas ( } 03 \text { aulas por } \\
\text { semana); } \\
\text { 3o ANO } 108 \text { horas/aula; } 90 \text { horas ( } 03 \text { aulas por } \\
\text { semana); } \\
\text { TOTAL } 270 \text { horas, ou } 324 \text { horas aulas }\end{array}$ \\
\hline
\end{tabular}

Fonte: A construção foi realizada a partir dos PPCs analisados.

Sobre a presença da Física no decorrer dos anos letivos, indicamos que esse é um fator importante no que tange a possibilidade de diálogo da 
Física junto a disciplinas do núcleo tecnológico. Em todos os planos de curso, a Física está presente nos três primeiros anos de formação, com no mínimo 210 horas, sendo a menor carga horária no campus de Barreiras, cujo curso dura 3 anos. Embora com menor carga horária, é em Barreiras que temos 0 componente curricular da Física presente em todo o período de formação do técnico em edificações, nos demais a presença é expressiva, e a Física enquanto disciplina se faz presente em 3 dos 4 anos do período de formação. A distribuição da Física em todo o período de formação, presente no campus Barreiras, aumenta a possibilidade de se criar articulações da Física junto as disciplinas de formação profissional pensando numa perspectiva de longo prazo e que contemple toda trajetória do estudante.

A respeito dos conteúdos para a disciplina de Física nos planos de curso, podemos chamá-los de clássicos, isso por trazerem aquilo que vem sendo apresentado nos livros didáticos, que se traduz para muitas escolas no currículo trabalhado. Em Barreiras, por exemplo, o conteúdo no $1^{\circ}$ ano parte da abordagem de grandezas físicas, caminhando por toda a mecânica até colisões. No $2^{\circ}$ ano, o início se dá na abordagem do conteúdo de gravitação universal, passando por mecânica dos fluidos, termodinâmica, óptica, movimento harmônico e parte de eletrodinâmica. Já no $3^{\circ}$ ano, há uma ênfase a eletrostática, ondas, magnetismo e física moderna, isso tudo numa distribuição de $80 \mathrm{~h}, 120 \mathrm{~h}$ e $80 \mathrm{~h}$ respectivamente.

O cenário do campus Barreiras se assemelha ao que vemos nos demais campi. Não há qualquer interlocução explícita entre os conteúdos trabalhados na disciplina de Física, com as disciplinas integrantes do núcleo tecnológico ou que faça menção a formação técnica onde o estudante está inserido. Isso reforça a constatação feita por Garcia (1995, p. 105) no âmbito das Escolas Técnicas Federais e CEFETs e análise feita por Souza e Penido $(2018,2019)$ no âmbito do curso de Segurança do Trabalho no IFBA campus Ilhéus. O elevado número de conteúdos próprios da Física contribui de forma negativa para a interlocução com a formação profissional técnica, já que, mesmo pensando a partir de um ensino médio regular, esses conteúdos encontram dificuldades em serem cumpridos em sua totalidade ou de terem a oportunidade de serem trabalhados a partir de outras metodologias de ensino que não a tradicional.

É relevante trazer que em todas as etapas para integralização do curso de edificações existem disciplinas do núcleo tecnológico. Nessas disciplinas, é notório uma expressiva quantidade de conteúdos que se interceptam com aqueles próprios da Física ou conteúdos da formação técnica cujos fundamentos da Física contribuem para sua compreensão. As disciplinas em que essa interseção é percebida são: Ensaios Tecnológicos, Instalações Elétricas e Telefônicas, Sistemas Estruturais, Instalações Hidrossanitárias e Resistência dos materiais, existindo uma predominância de conteúdos de mecânica, seguido de fundamentos básicos de eletricidade. 
Se tomarmos como exemplo o PPC do campus de Barreiras, integram as disciplinas do núcleo tecnológico para o $1^{\circ}$ ano, Desenho Arquitetônico I, Informática Aplicada e Mecânica dos solos; no $2^{\underline{0}}$ ano, Tecnologia das Construções, Mecânica dos solos II, Desenho Arquitetônico II e Resistência dos Materiais; no $3^{\circ}$ ano, Estrutura de Concreto, Instalações Hidrossanitárias, Planejamento e Gerenciamento de obras - PGO, Topografia e Instalações Elétricas. Ao olhar para a descrição de cada um desses componentes curriculares, foi possível listar os seguintes conteúdos comuns a Física: a) Grandezas fundamentais: força, momento e binário; b) Condições de equilíbrio; c) Tensões e deformações na flexão; d) Esforços axiais: tensões e deformações, lei de Hooke, diagrama tensão x deformação; e) Conceitos básicos de eletricidade. Além destes, conteúdos que requerem noções de área, volume, unidades de medida, interpretação de gráficos, que são trabalhados no decorrer da apresentação dos conteúdos da Física, permeiam grande parte das disciplinas do núcleo tecnológico.

Embora os planos de curso analisados correspondam a campi que nasceram em momentos históricos diferentes da Rede Federal, não foram percebidas características que os diferenciem na sua essência, salvo a exceção da PPA no campus Barreiras, que também já se apresenta como uma perspectiva para os demais campi a partir de projetos de reformulação e implantação de novos cursos de Ensino Médio Integrado. A semelhança acontece tanto quanto aos conteúdos, como na distribuição de carga horária no decorrer das séries letivas, formas de avaliação, metodologia e referências bibliográficas. As particularidades podem ser encontradas na síntese que apresentamos na Quadro 3.

Quadro 3 - Quadro resumo dos elementos do componente curricular da Física que fazem referência a parte da formação profissional do curso.

\begin{tabular}{|c|l|}
\hline Campus & $\begin{array}{l}\text { Elementos do componente curricular da Física que fazem } \\
\text { referência a formação profissional técnica pretendida. }\end{array}$ \\
\hline Barreiras & $\begin{array}{l}\text { Conteúdos: Conteúdos próprios do ensino médio regular. } \\
\text { Metodologia: Não há menção a formação profissional. A } \\
\text { metodologia concentra-se em aulas expositivas, exercícios e aulas } \\
\text { Aváticasano: Não há um instrumento que evidencie a aspectos } \\
\text { próprios da formação profissional do estudante. } \\
\text { Referências Bibliográficas: Não há referências bibliográficas que } \\
\text { tragam conteúdos da área profissional técnica. Os livros são os } \\
\text { comumente trabalhados no ensino médio regular. }\end{array}$ \\
\hline Eunápolis & \\
\hline
\end{tabular}




\begin{tabular}{|c|c|}
\hline & $\begin{array}{l}\text { Conteúdos: Conteúdos próprios do ensino médio regular. } \\
\text { Metodologia: Não há menção a formação profissional. A } \\
\text { metodologia concentra-se em aulas expositivas, exercícios e aulas } \\
\text { práticas. } \\
\text { Avaliação: Não há um instrumento que evidencie a aspectos } \\
\text { próprios da formação profissional do estudante. } \\
\text { Referências Bibliográficas: Não há referências bibliográficas que } \\
\text { tragam conteúdos da área profissional técnica. Os livros são os } \\
\text { comumente trabalhados no ensino médio regular. }\end{array}$ \\
\hline $\begin{array}{l}\text { Feira de } \\
\text { Santana }\end{array}$ & $\begin{array}{l}\text { Conteúdos: Conteúdos próprios do ensino médio regular. } \\
\text { Metodologia: Não há menção a formação profissional. A } \\
\text { metodologia concentra-se em aulas expositivas, exercícios e aulas } \\
\text { práticas. } \\
\text { Avaliação: Não há um instrumento que evidencie a aspectos } \\
\text { próprios da formação profissional do estudante. } \\
\text { Referências Bibliográficas: Não há referências bibliográficas que } \\
\text { tragam conteúdos da área profissional técnica. Os livros são os } \\
\text { comumente trabalhados no ensino médio regular. }\end{array}$ \\
\hline Ilhéus & $\begin{array}{l}\text { Conteúdos: Conteúdos próprios do ensino médio regular. } \\
\text { Metodologia: Não há menção a formação profissional. A } \\
\text { metodologia concentra-se em aulas expositivas, exercícios e aulas } \\
\text { práticas. } \\
\text { Avaliação: Não há um instrumento que evidencie a aspectos } \\
\text { próprios da formação profissional do estudante. } \\
\text { Referências Bibliográficas: Não há referências bibliográficas que } \\
\text { tragam conteúdos da área profissional técnica. Os livros são os } \\
\text { comumente trabalhados no ensino médio regular. }\end{array}$ \\
\hline Salvador & $\begin{array}{l}\text { Conteúdos: Conteúdos próprios do ensino médio regular. } \\
\text { Metodologia: QUESTÕES APLICADAS - pesquisa bibliográfica sobre } \\
\text { temas de aprofundamento do curso técnico do aluno. } \\
\text { Avaliação: Não há um instrumento que evidencie a aspectos } \\
\text { próprios da formação profissional do estudante. } \\
\text { Referências Bibliográficas: Não há referências bibliográficas que } \\
\text { tragam conteúdos da área profissional técnica. Os livros são os } \\
\text { comumente trabalhados no ensino médio regular. }\end{array}$ \\
\hline
\end{tabular}

Fonte: A construção foi realizada pelos próprios autores, a partir dos PPCs analisados.

Dos dados da Quadro 3, no campus Salvador vemos, em Metodologia, as QUESTÕES APLICADAS que fazem menção ao aprofundamento da Física 
ao curso técnico do aluno, embora apenas pela citação presente no PPC, não é possível compreender como essa interlocução se processa. Já em conteúdos, avaliação e referências bibliográficas, a relação junto a formação profissional técnica não aparece. A ausência de referências bibliográficas que dialoguem com o curso de edificações pode reforçar a ideia do tratamento clássico dado a disciplina mas também pode ser um indicativo da utilização de material didático produzido pelo próprio docente quando se pensa na Física para o curso; sobre esse aspecto achamos relevante que o mesmo seja abordado numa pesquisa posterior.

\section{CONSIDERAÇÕES FINAIS}

A proposta desse artigo foi perceber elementos na descrição do componente curricular da Física nos Projetos Pedagógicos de Curso do IFBA que apresentassem um esforço na construção de um ensino de Física para 0 Ensino Médio Integrado, visando a formação plena do sujeito e a sua habilitação enquanto profissional técnico; para isso partimos da análise do componente curricular na busca de entender a distribuição e organização da disciplina de Física nos cursos de ensino médio integrado, os elementos do currículo de Física que fazem menção a formação profissional técnica ou que contribuam para a consolidação da educação politécnica e os conteúdos que são comuns tanto a Física quanto as disciplinas do núcleo tecnológico.

A partir da nossa pesquisa verificamos que não existe indicação explícita que tome a politecnia como balizadora para abordagem da disciplina de Física no curso pesquisado e que a disposição dos conteúdos e temas da Física presentes nos cursos técnicos em edificações em nada diferem do que comumente é proposto para o ensino médio regular. Um fator relevante é a existência de uma quantidade de conteúdos considerável que se apresentam tanto na disciplina de Física, como nas disciplinas do núcleo tecnológico. Isso nos aponta a possibilidade de pensarmos em currículos para a Física em cursos técnicos de edificações que mantenham a mesma ou maior capacidade de formação partindo de uma integração mais efetiva. Isso se consolida a partir da garantia da ciência básica Física no currículo, mas que tome a habilitação profissional onde o estudante está sendo formado como vetor para pensar a apresentação e profundidade de cada conteúdo, pensando na interface ciência básica e ciência aplicada.

Apesar do PPI do Instituto Federal da Bahia fazer referência a educação politécnica apresentada por Saviani, não há elementos na descrição do componente curricular da Física que evidencie a sua elaboração com base nesse referencial teórico. Dito isto, pontuamos a urgente necessidade de repensar os PPCs. Para isso, sugerimos a necessidade de um constante diálogo entre os professores da área de Física, professores do núcleo tecnológico e das coordenações de curso, para que esses sujeitos 
compreendam como seu campo de atuação pode contribuir na formação do futuro técnico em edificações, o que dá significado a presença das diferentes especialidades num curso de formação técnica integrado.

Do ponto de vista curricular, apontamos como perspectiva futura desse trabalho, a pesquisa e análise dos projetos das PPA (junto a sua execução), a análise de como os PPCs influenciam nos planos de ensino docente no decorrer das unidades letivas e o diálogo com os docentes que ministram aulas de Física no EMI em edificações desses campi, de modo a verificar como o que aparece nos documentos oficiais ressoam na execução das atividades em sala de aula.

\section{REFERÊNCIAS}

BRASIL. Lei no 9.394, de 20 de dezembro de 1996. Estabelece as diretrizes e bases da educação nacional. Este texto não substitui o publicado no DOU de 23.12.1996. Disponível em: http://www.planalto.gov.br/Ccivil_03/leis/L9394.htm. Acesso em: 30/03/2018.

BRASIL. Decreto no 2.208, de 17 de abril de 1997. Regulamenta o $\S 2$ 으 do art. 36 e os arts. 39 a 42 da Lei no 9.394, de 20 de dezembro de 1996, que estabelece as diretrizes e bases da educação nacional. DOU de 18.4.1997. Disponível em: http://www.planalto.gov.br/ccivil 03/decreto/d2208.htm. Acesso em: 30/03/2018.

BRASIL. Decreto no 5.154 de 23 de julho de 2004. Regulamenta $\circ \S 2$ 으 do art. 36 e os arts. 39 a 41 da Lei no 9.394, de 20 de dezembro de 1996, que estabelece as diretrizes e bases da educação nacional, e dá outras providências. 26.7.2004. 2004a. Disponível em: http://www.planalto.gov.br/ccivil_03/_ato2004-2006/2004/decreto/d5154.htm. Acesso em 30/03/2018.

BRASIL. Lei no 11.982, de 28 de dezembro de 2008. Institui a Rede Federal de Educação Profissional, Científica e Tecnológica, cria os Institutos Federais de Educação, Ciência e Tecnologia, e dá outras providências. DOU de 30 de dezembro de 2008. Pág. 01.

BRASIL. Ministério da Educação/ MEC. Catálogo Nacional de Cursos Técnicos. 3. ed. Brasília: MEC, 2016.

CIAVATTA, Maria. A formação integrada: a escola e o trabalho como lugares de memória e de identidade. In: RAMOS, Marise. (Org.); FRIGOTTO, Gaudêncio (Org.); CIAVATTA, Maria (Org.). Ensino Médio Integrado: Concepção e Contradições. São Paulo: Cortez, 2012; pp. 83-105.

FRANCA, Frank Hebert Pires. Uma sequência didática para o de conceitos de mecânica quântica utilizando os raios x sob a perspectiva sociocultural. In: XXIII Simpósio Nacional de Ensino de Física, 2019, Salvador. Anais do XXIII Simpósio Nacional de Ensino de Física, 2019. 
FRIGOTTO, Gaudêncio; CIAVATTA, Maria; RAMOS, Marise. A gênese do decreto n. 5.154/2004: um debate no contexto controverso da democracia restrita. In: RAMOS, Marise; FRIGOTTO, Gaudêncio; CIAVATTA, Maria (Orgs.). Ensino Médio Integrado: Concepção e Contradições. 3. ed. São Paulo: Cortez, 2012; pp. 21-56.

GARCIA, Nilson Marcos Dias. A Física no Ensino Técnico Industrial Federal: um retrato em formado A4. 1995. Dissertação (Mestrado em Ensino de Ciências (Modalidades Física e Química)). Universidade de São Paulo, São Paulo.

IFBA. Resolução CONSUP, no 30/CONSUP, de 24/05/2016: Instrução Normativa Pedagógica para Reformulação Curricular dos Cursos da Educação Profissional Técnica de Nível Médio, Forma Integrada. Disponível em: http://portal.ifba.edu.br/menu-institucional/consup/resolucoes-2016/resol-no-302016-anexo.pdf. Acesso em 31/08/2018.

IFBA. Projeto Pedagógico Institucional do IFBA. Salvador, 2013. Disponível em: http://portal.ifba.edu.br/menu-institucional/documento/documentosinstitucionais. Acesso em 02/04/2018.

IFBA. Instituto Federal da Bahia - Processo Seletivo IFBA 2018. 2018. Disponível em: http://portal.ifba.edu.br/menu-campi/escolha-o-campus. Acesso em 02/04/2018.

IFBA. Projeto Pedagógico do Curso Técnico de Nível Médio em Edificações, Forma: Integrada ao Ensino Médio, campus Eunápolis, 2011.

IFBA. Projeto Pedagógico do Curso Técnico de Nível Médio em Edificações, Forma: Integrada ao Ensino Médio, campus Feira de Santana, 2011.

IFBA. Projeto Pedagógico do Curso Técnico de Nível Médio em Edificações, Forma: Integrada ao Ensino Médio, campus Salvador, 2011.

IFBA. Projeto Pedagógico do Curso Técnico de Nível Médio em Edificações, Forma: Integrada ao Ensino Médio, campus Barreiras, 2016.

IFBA. Projeto Pedagógico do Curso Técnico de Nível Médio em Edificações, Forma: Integrada ao Ensino Médio, campus Ilhéus, 2016.

MOURA, Dante Henrique. Educação básica e educação profissional e tecnológica: dualidade histórica e perspectivas de integração. Revista Holos., v.2, p. 4 -30, mar. 2007.

MOURA, Dante Henrique; GARCIA, Sandra Regina de Oliveira; RAMOS, Marise Nogueira. Ministério da Educação. Educação Profissional Técnica de Nível Médio Integrada ao Ensino Médio: Documento Base, 2007.

RAMOS, Marise. Concepção do ensino médio integrado. In: SEMINÁRIO SOBRE ENSINO MÉDIO, 2008. Secretaria de Educação do Pará. 08-09 maio 2008. Disponível em: https://tecnicadmiwi.files.wordpress.com/2008/09/textoconcepcao-do-ensino-medio-integrado-marise-ramos1.pdf 
RAMOS, Marise. Possibilidades e desafios na organização do currículo integrado. In: RAMOS, Marise; FRIGOTTO, Gaudêncio; CIAVATTA, Maria. Ensino Médio Integrado: Concepção e Contradições. 3. ed. São Paulo: Cortez, 2012; pp. 107-128.

ROCHA, Jonyson Marcs Borges da; MELO, Claudia Adriana de Sousa. Uso de material paradidático para a montagem de dispositivos térmicos caseiros no ensino profissionalizante para o estudo da calorimetria. In: XXIII Simpósio Nacional de Ensino de Física, 2019, Salvador. Anais do XXIII Simpósio Nacional de Ensino de Física, 2019.

SAVIANI, Dermeval. Sobre a concepção de politecnia. Rio de Janeiro: FIOCRUZ. Politécnico da Saúde Joaquim Venâncio, 1989.

SAVIANI, Dermeval. Trabalho e educação: fundamentos ontológicos e históricos. Revista Brasileira de Educação. 2007, vol.12, n.34, pp. 152-165.

SIMÕES, Carlos Artexes. Juventude e Educação Técnica: a experiência na formação de jovens trabalhadores da Escola Estadual Prof. Horácio Macedo/CEFET-RJ. Dissertação de Mestrado. Niterói, UFF, 2007.

SOUZA, D. A.; PENIDO, M. C. M. . O currículo de Física na educação profissional técnica de nível médio: quais elementos do plano de curso favorecem a integração?. In: XXIII Simpósio Nacional de Ensino de Física, 2019, Salvador. Anais do XXIII Simpósio Nacional de Ensino de Física, 2019.

SOUZA, D. A.; PENIDO, M. C. M. . O ensino de física na educação tecnológica integrada de nível médio: reflexões a partir do plano de curso de uma instituição da rede federal de educação profissional tecnológica. In: III Congresso Nacional de Pesquisa e Ensino em Ciências, 2018, Campina Grande. Anais do III Congresso Nacional de Pesquisa e Ensino em Ciências, 2018. 